\title{
Modified FCS-MPC algorithm for five-leg voltage source inverter
}

\author{
Riyadh G. Omar \\ Department of Electrical Engineering, College of Engineering, University of Mustansiriyah, Iraq
}

\begin{tabular}{|c|c|}
\hline Article Info & ABSTRACT \\
\hline Article history: & This paper represents a test of a modified algorithm to minimize the \\
\hline Received Jul 2, 2019 & $\begin{array}{l}\text { cost function in the traditional finite control-set model predictive current } \\
\text { control (FCS-MPC) to control the (five-leg) DC voltage input inverter. A }\end{array}$ \\
\hline Revised Jan 3, 2020 & Matlab/Simulink description of a system presents a certain deviation limits \\
\hline Accepted Jan 14, 2020 & $\begin{array}{l}\text { between the reference and the actual measured phase currents, also the model } \\
\text { implements a load current limitation. The algorithm picks out a proper }\end{array}$ \\
\hline Keywords: & $\begin{array}{l}\text { Switching state, which makes the lower error value between the wanted and } \\
\text { the prognosticated currents; the proposed technique sets the chosen switching }\end{array}$ \\
\hline Cost-function constraints & state as a driving signal to the ten switches. The modified program eliminates \\
\hline five-leg DC voltage input & $\begin{array}{l}\text { the switching combination with error values above the requested ones. } \\
\text { Thereafter the system response enhanced by lowering the overshoots. }\end{array}$ \\
\hline MPC & The rigidness of the model is examined by using a step change in reference \\
\hline SVPWM & signals. \\
\hline
\end{tabular}

Copyright $(0) 2020$ Institute of Advanced Engineering and Science. All rights reserved.

\section{Corresponding Author:}

Riyadh G. Omar,

Department of Electrical Engineering, College of Engineering,

University of Mustansiriyah, Baghdad, Iraq.

Email: dyala1968@gmail.com

\section{INTRODUCTION}

In recent years, many applications in $\mathrm{AC}$ machines require a higher number of supply phases. This can be accomplished by power electronics drives. The multi-phase AC drives supplied from more than three phase voltage source inverters which, controlled by various methods. The former introduction of five-leg DC voltage input inverter driving a multi-phase induction motor was proposed by Ward and Harer in 1969 [1-4]. Predictive control spread widely in the past years and it proved the superiority over the other PWM techniques [5-14].

The essence of this strategy of control based on the system parameters model, to forecast the next act of the specified variables, later the controller employs this prediction with the aid of optimization procedure to obtain the most suitable control commands. Many advantages is gained by implementing the MPC and make this strategy suitable in power electronics converters control, this because its easiness to acquire, the major drawback of this choice is the need for a high speed computers due to the considerable figure of mathematical calculations. The finite current set technique (FCS-MPC) is one of the main outcome of the predictive control since it employs one close control loop (load current), to calculate the minimum error between the predetermined reference and the measured current to predict the next control action. In this work, a modified algorithm is used by adding defined error, and maximum current constraints to the cost function which responsible of produce the required commands is presented to drive the five-leg DC voltage input inverter. 


\section{FIVE-LEG VSI MODEL}

The structure of this type of inverters is illustrated in Figure 1; the inverter has ten IGBT switching elements numbered from one to ten the two IGBT's in the same leg must not conduct in the same time to prevent short-circuiting the battery source. This inverter has $(25=32)$ switching states. The load voltage totally relies upon each switching state combination; these switches links the two Battery terminals to the load. This work handles a load with R-L filter; the new strategy can be likewise extended to manage various loads and filters. The underlying advance of surmising the mathematical model of the inverter is by delineating the dependence of the load voltages on the exchanging signal requests.

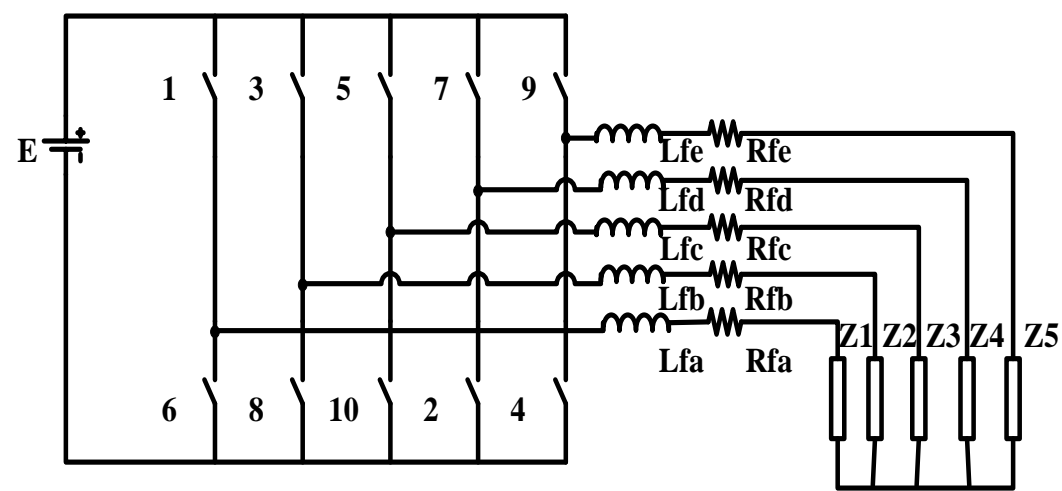

Figure 1. 5-leg VSI

$$
\left[\begin{array}{c}
\mathrm{v}_{\mathrm{an}} \\
\mathrm{v}_{\mathrm{bn}} \\
\mathrm{v}_{\mathrm{cn}} \\
\mathrm{v}_{\mathrm{dn}} \\
\mathrm{v}_{\mathrm{en}}
\end{array}\right]=\left[\begin{array}{l}
\mathrm{S}_{1} \\
\mathrm{~S}_{3} \\
\mathrm{~S}_{5} \\
\mathrm{~S}_{7} \\
\mathrm{~S}_{9}
\end{array}\right] . \mathrm{E}
$$

from Figure 1. The inverter terminal voltages are:

$$
\left.\begin{array}{l}
\mathrm{v}_{\mathrm{an}}=\mathrm{R}_{t a} \mathrm{i}_{\mathrm{oa}}+\mathrm{L}_{\mathrm{fa}} \frac{\mathrm{di}_{\mathrm{oa}}}{\mathrm{dt}} \\
\mathrm{v}_{\mathrm{bn}}=\mathrm{R}_{t b} \mathrm{i}_{\mathrm{ob}}+\mathrm{L}_{\mathrm{fb}} \frac{\mathrm{di}_{\mathrm{ob}}}{\mathrm{dt}} \\
\mathrm{v}_{\mathrm{cn}}=\mathrm{R}_{t c} \mathrm{i}_{\mathrm{oc}}+\mathrm{L}_{\mathrm{fc}} \frac{\mathrm{d \textrm {i } _ { \mathrm { oc } }}}{\mathrm{dt}} \\
\mathrm{v}_{\mathrm{dn}}=\mathrm{R}_{t d} \mathrm{i}_{\mathrm{od}}+\mathrm{L}_{\mathrm{fd}} \frac{\mathrm{di} \mathrm{od}_{\mathrm{od}}}{\mathrm{dt}} \\
\mathrm{v}_{\mathrm{en}}=\mathrm{R}_{t e} \mathrm{i}_{\mathrm{oe}}+\mathrm{L}_{\mathrm{fe}} \frac{\mathrm{di}_{\mathrm{oe}}}{\mathrm{dt}}
\end{array}\right\}
$$

where,

$\mathrm{R}_{\mathrm{ta}}, \mathrm{R}_{\mathrm{tb}}, \mathrm{R}_{\mathrm{tc}}, \mathrm{R}_{\mathrm{td}}$, and $\mathrm{R}_{\mathrm{te}}$ are (a, b, c, d, and e) phase resistances.

$\mathrm{L}_{\mathrm{fa}}, \mathrm{L}_{\mathrm{fb}}, \mathrm{L}_{\mathrm{fc}}, \mathrm{L}_{\mathrm{fd}}$ and $\mathrm{L}_{\mathrm{fe}}$ are (a, b, c, d, and e) phase filter inductances.

$\mathrm{i}_{\mathrm{oa}}, \mathrm{i}_{\mathrm{ob}}, \mathrm{i}_{\mathrm{oc}}, \mathrm{i}_{\mathrm{od}}$ and $\mathrm{i}_{\mathrm{oe}}$ are the (a, b, c, d, and e) phase load currents.

putting in a matrix form as:

$$
\mathrm{v}_{\mathrm{o}}=\mathrm{R}_{t} \mathrm{i}_{\mathrm{o}}+\mathrm{L}_{\mathrm{f}} \frac{\mathrm{di}_{\mathrm{o}}}{\mathrm{dt}}
$$

The instant load current can be calculated from (3) as follows:

$$
\frac{\mathrm{di}_{\mathrm{o}}}{\mathrm{dt}}=\frac{1}{\mathrm{~L}_{\mathrm{f}}}\left[\mathrm{v}_{\mathrm{o}}-R_{t} \mathrm{i}_{\mathrm{o}}\right]
$$




\section{THE CURRENT CONTROL USING FCS-MPC WITH LEAST CURRENT ERROR AND MAXIMUM CURRENT CONSTRAINTS.}

The structure of this control strategy is based on the cost function reduction. This strategy is used widely in power converters employments over the latest years, in light of its straightforward thought, and rapid [14-16]. The key steps, which are carried out in this technique, are as follow:

a) Reading the real actual current at each instant.

b) Creating a reference value dependent on the desired implementation.

c) Finally producing the discrete predictive model based on inverter parameters.

In this work and for tolerable accuracy the discrete structure is constructed by applying first-order approximation to the derivatives [17-25].

$$
\frac{d i_{o}}{d t}=\frac{i_{0}(K+1)-i_{0}(K)}{T_{s}}
$$

Putting (5) in (4) yields:

$$
\mathrm{i}_{\mathrm{o}}(\mathrm{K}+1)=\frac{\mathrm{T}_{\mathrm{s}}}{\mathrm{L}_{\mathrm{f}}+\mathrm{R}_{\mathrm{t}} \mathrm{T}_{\mathrm{s}}} \mathrm{V}_{\mathrm{o}}(\mathrm{K})+\frac{\mathrm{L}_{\mathrm{f}}}{\mathrm{L}_{\mathrm{f}}+\mathrm{R}_{\mathrm{t}} \mathrm{T}_{\mathrm{s}}} \mathrm{i}_{\mathrm{o}}(\mathrm{k})
$$

The (32) switching available combination can be handled by the proposed program to calculate $\operatorname{vo}(\mathrm{K})$, this will give a (32) various predictions of the next instant io $(\mathrm{K}+1)$. The program is designed to selects the right switching combination at $\mathrm{k}^{\text {th }}$ instant, which, produce the least possible error results from subtracting the estimated actual current and the required reference current value $[$ io* $(K+1)$ - io $(K+1)]$ at the future instant of time $(\mathrm{K}+1)$. This switching combination is utilized as a control action to inverter switches.

The cost function $(\mathrm{g})$ governing the process is:

$$
\begin{aligned}
& g(K+1)=\left\|i_{o}^{*}(K+1)-i_{o}(K+1)\right\|=\left\|i_{o a}^{*}(K+1)-i_{o a}(K+1)\right\|+\left\|i_{o b}^{*}(K+1)-i_{o b}(K+1)\right\| \\
& +\left\|i_{o c}^{*}(K+1)-i_{o c}(K+1)\right\|+\left\|i_{o d}^{*}(K+1)-i_{o d}(K+1)\right\|+\left\|i_{o e}^{*}(K+1)-i_{o e}(K+1)\right\|+ \\
& f 1+\ldots+f 10
\end{aligned}
$$

If the sampling time Ts $\leq 20 \mu$ s extrapolation process is not required [10], so that the desired current at $(\mathrm{K})$ instant= desired current at $(\mathrm{K}+1)$ instant [9].

The proposed algorithm define the function (f) which represents the predefined load current boundaries and maximum allowed error. These functions $\left(\mathrm{f}_{1} \ldots . . \mathrm{f}_{10}\right)$ are appear as a constraint in the cost function (8), therefor any violation to these constraint, will exclude this cost function value, and the corresponding switching combination from the solution. This can be achieved by enlarging the result of (8).

\section{SIMULATION OF THE MODIFIED TECHNIQUE}

The 5-leg DC voltage input inverter Matlab/Simulink model using the FCS-MPC technique is clarified in Figure 2. The components used in the simulation are (filter resistor $=0.7 \Omega$, filter inductor $=15 \mathrm{mH}$, load resistor $=10 \Omega$, and switching time $=20 \mu \mathrm{sec}$ ). The VSI subsystem block, includes of two subsystems block, see Figure 3. The first one is (inverter1), which contains the five-leg inverter. The inverter switches are SEMKRON (SKM50GAL12T4) IGBT type, the switches data (fall time, rise time, and tail time) are used in inverter model (IGBT block). The specifics of (inverter1) are shown in Figure 4.

The MPC subsystem is shown in Figure 5. The main object in this subsystem is the S-function block named (mpcc5) were its inputs are the three-phase desired currents and the actual measured load currents. The M-file program established in this block performs the FCS-MPC modified algorithm. The output of this subsystem is the inverter switching commands as shown in Figure 5. Each output switching state acts as the proper switching combination which produces the optimal cost function value (i.e. least error) at the $(\mathrm{K}+1)$ period. 


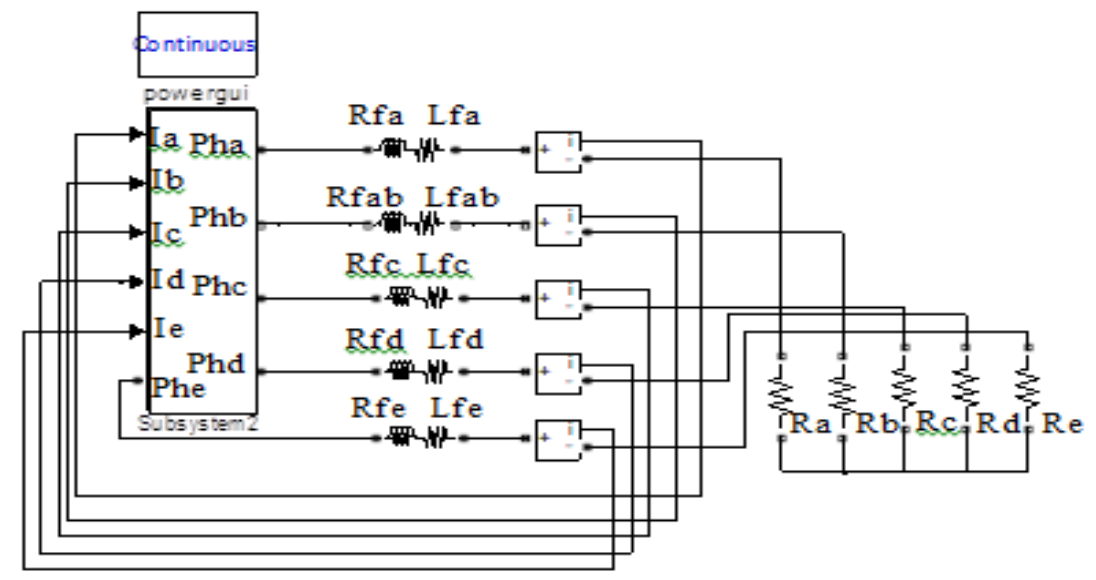

Figure 2. Actualized Matlab/Simulink model of proposed technique

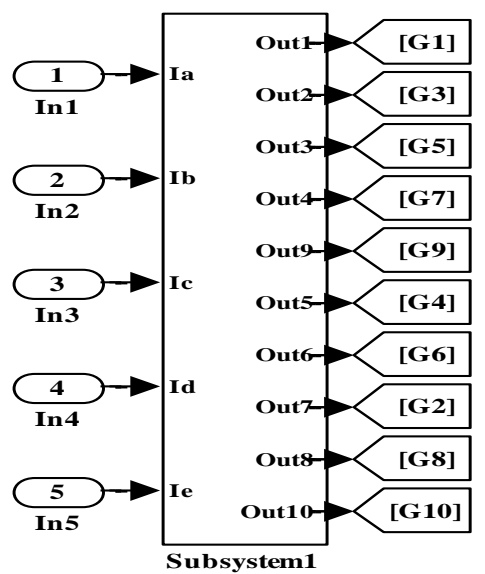

Figure 3 The inner subsystem included in the inverter block

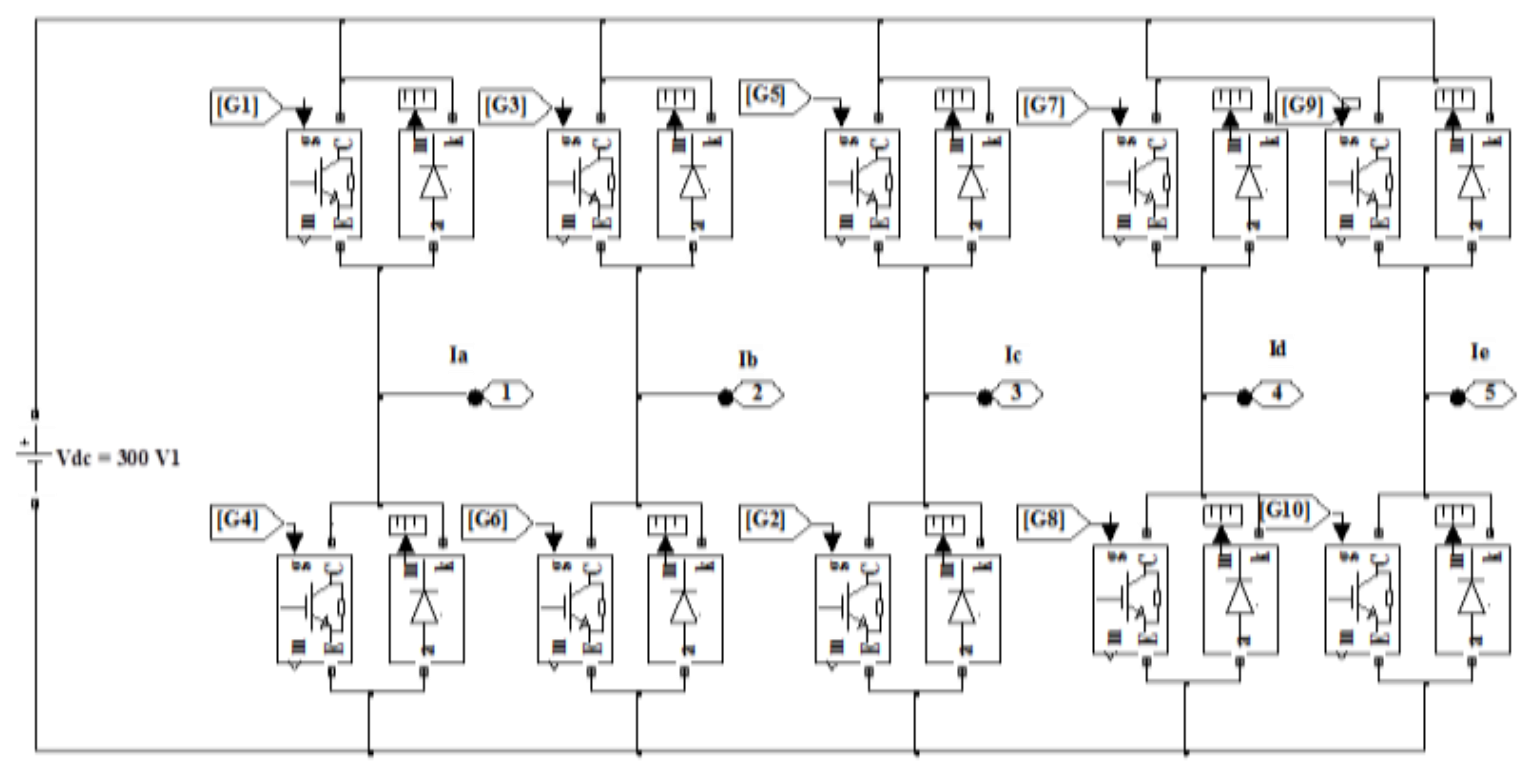

Figure 4. (Inverter1) subsystem 

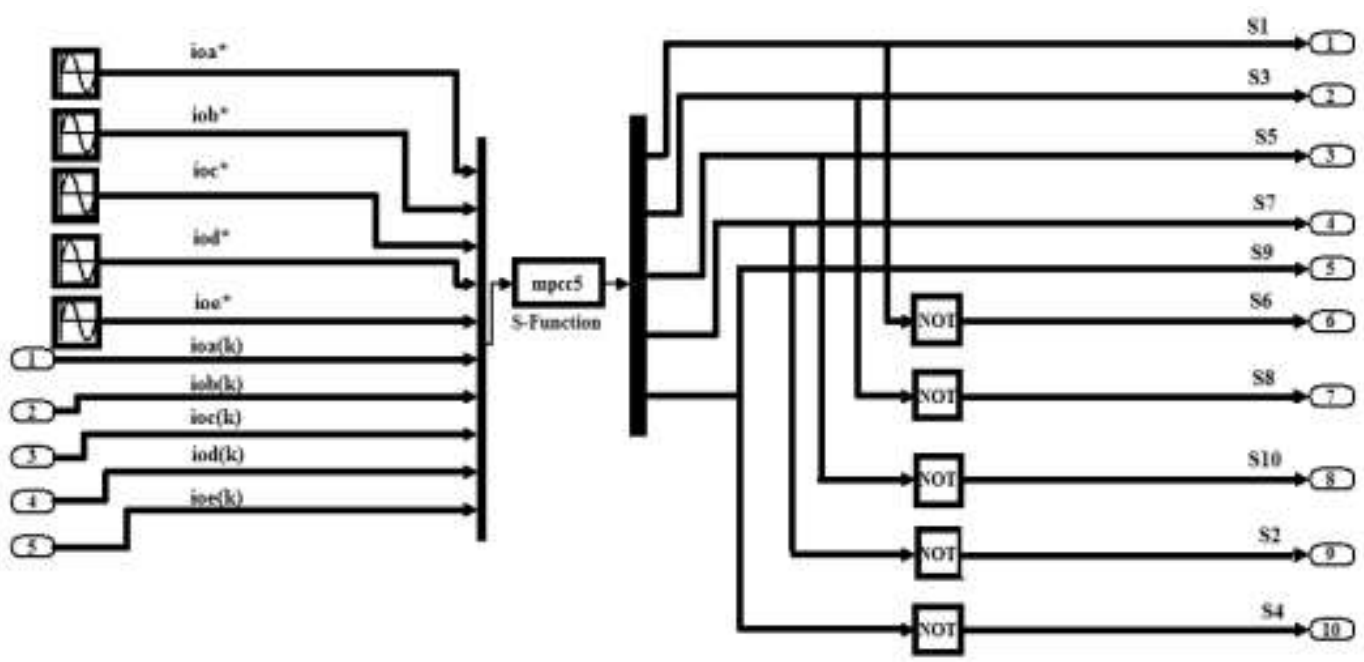

Figure 5. The MPC block

\section{SIMULATION RESULTS}

The simulation is achieved using Matlab/Simulink program, the goal is to optimize the cost function using extreme current limit and least error results from subtracting the estimated actual current and the required reference current value. The computation process is performed with two cases: 1- steady-state and step-change; the type of cost function used in this work is minimum absolute value. Figures 6-9 present the inverter $5-\varnothing$ terminals voltages, actual measured $5-\varnothing$ currents for both the traditional and the modified algorithm (maximum current and minimum currents error constraints). These results show the superiority of the proposed algorithm by reducing the overshoots. Figures 10-14 indicates an examination between the wanted 5- $\varnothing$ currents versus the relating measured actual currents. These figures demonstrate the abridgement coordinating the two (anticipated and the reference values). As mentioned before, the algorithm selects the proper switching combination that yields the lowest cost function, which can be seen in Figure 15. Figure 16 illustrate the agreeable (THD) of the modified algorithm for the five-leg inverter output voltage.

To certify the authenticity and the quality of the FCS-MPC current control with maximum current and leas current error constraints technique, a mathematical analysis with different load in each phase with equal desired currents is implemented. The 5- $\varnothing$ load voltages for this case study is illustrated in Figure 17. For this case-study, correlations include the real 5-leg currents, with the 5-leg comparable desired values is clarified in Figure 18. This outcome demonstrates that, in spite of the fact that the presences of unequal loads in each phase, the 5- $\varnothing$ load currents pursue and nearly coordinate the ideal adjusted desired current values.

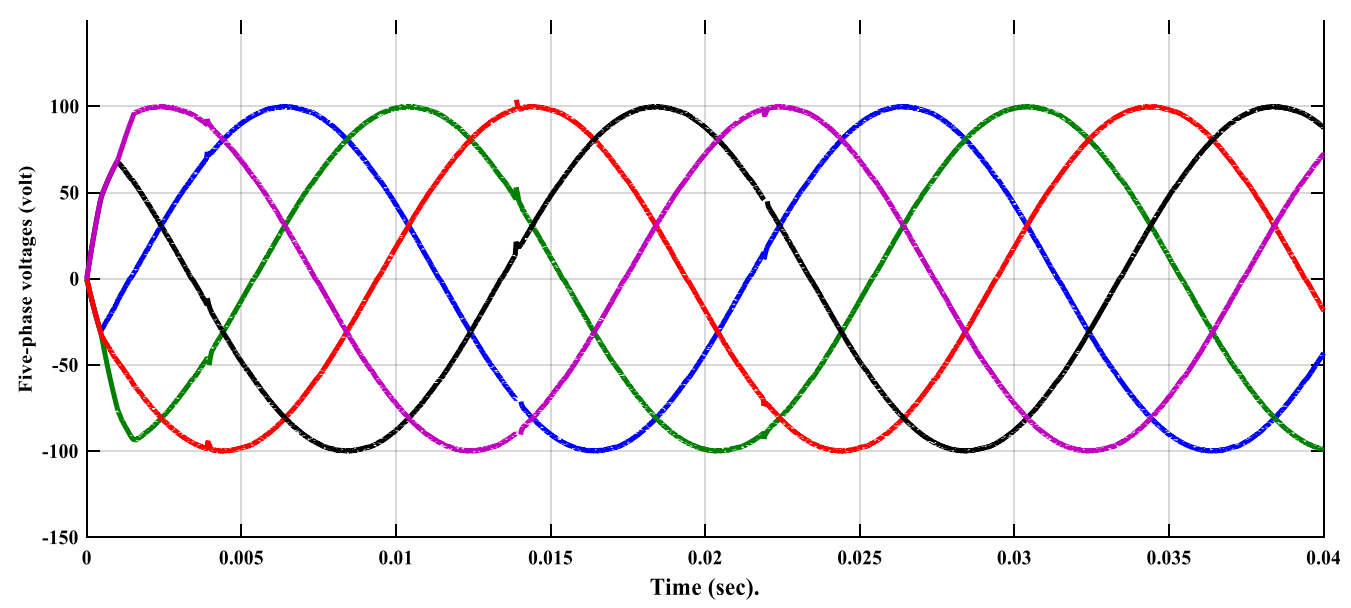

Figure 6. 5- $\varnothing$ output voltages with modified voltages 


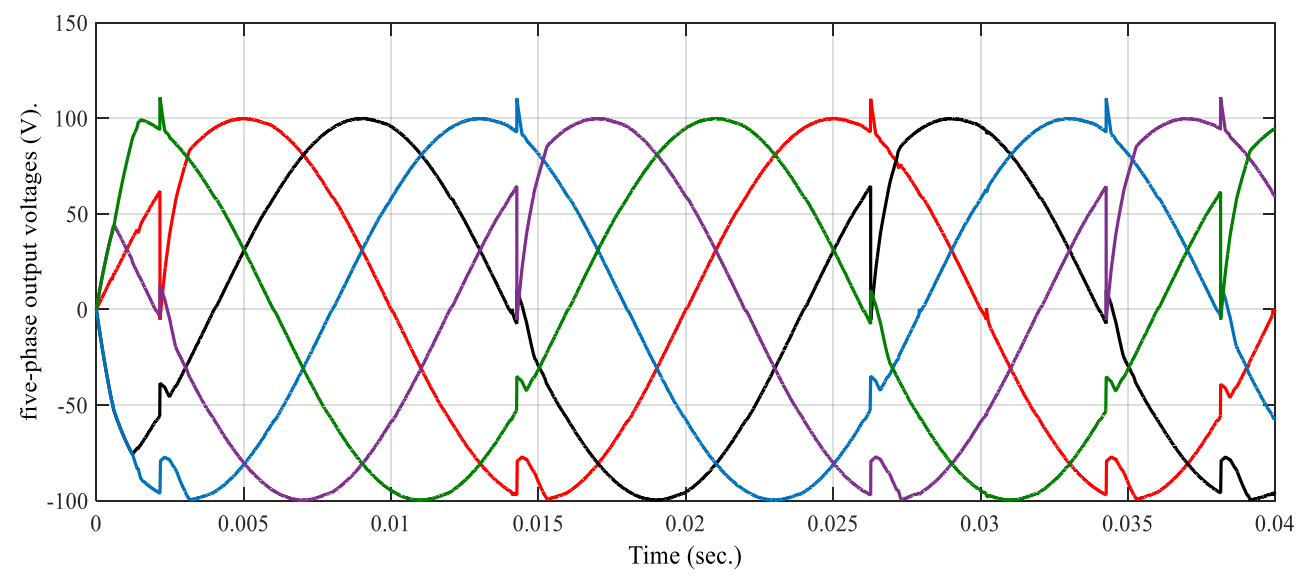

Figure 7. Traditional 5- $\varnothing$ output load algorithm

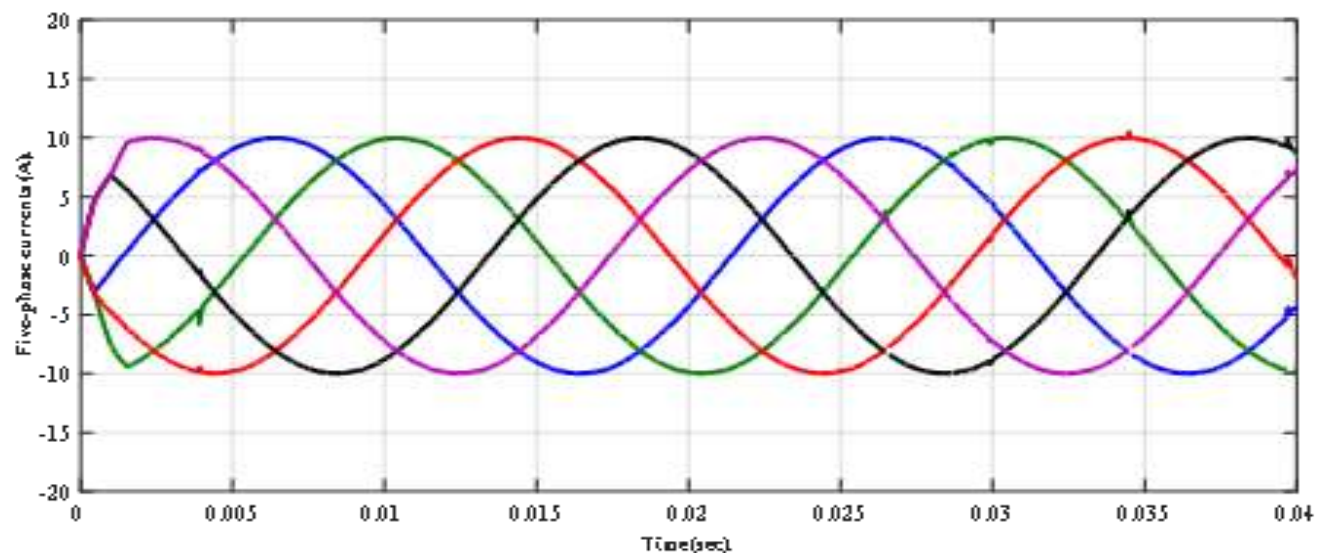

Figure 8. Traditional 5- $\varnothing$ load currents algorithm

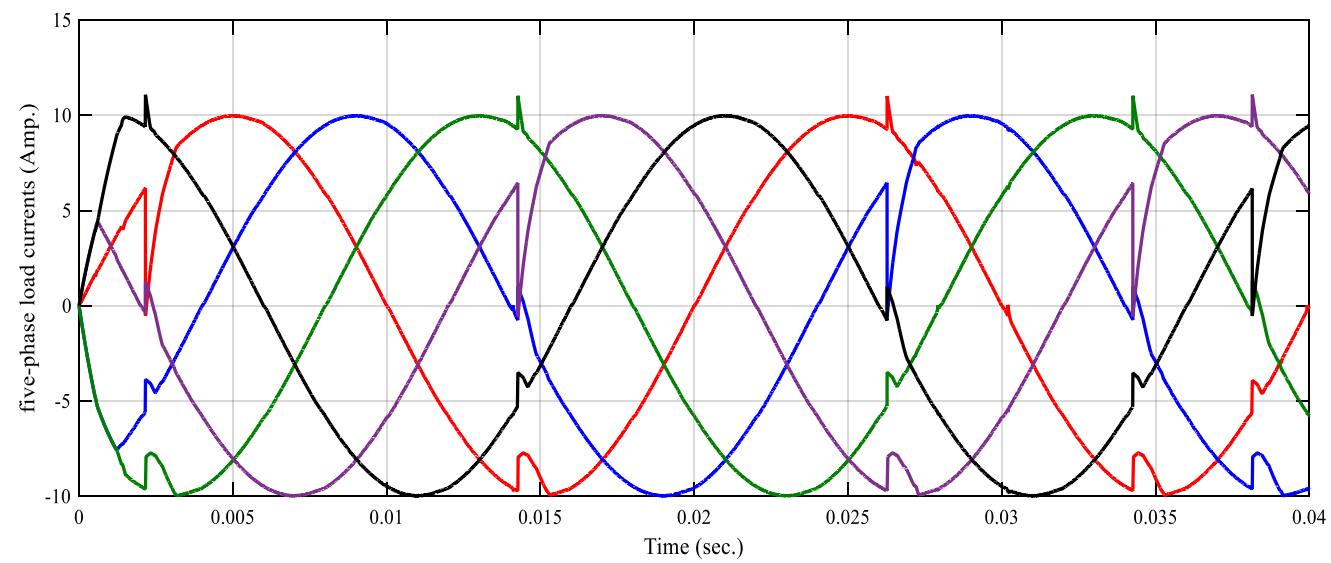

Figure 9. 5- $\varnothing$ load currents with modified

The last relevant examination is applying a step-change in the desired current values. Figures 19-20 illustrate the 5- $\varnothing$ load current values and voltages under a step-change at $0.01 \mathrm{sec}$. This demonstrate the sufficiency of the proposed algorithm, it is robust against the transient change in the desired current values. 


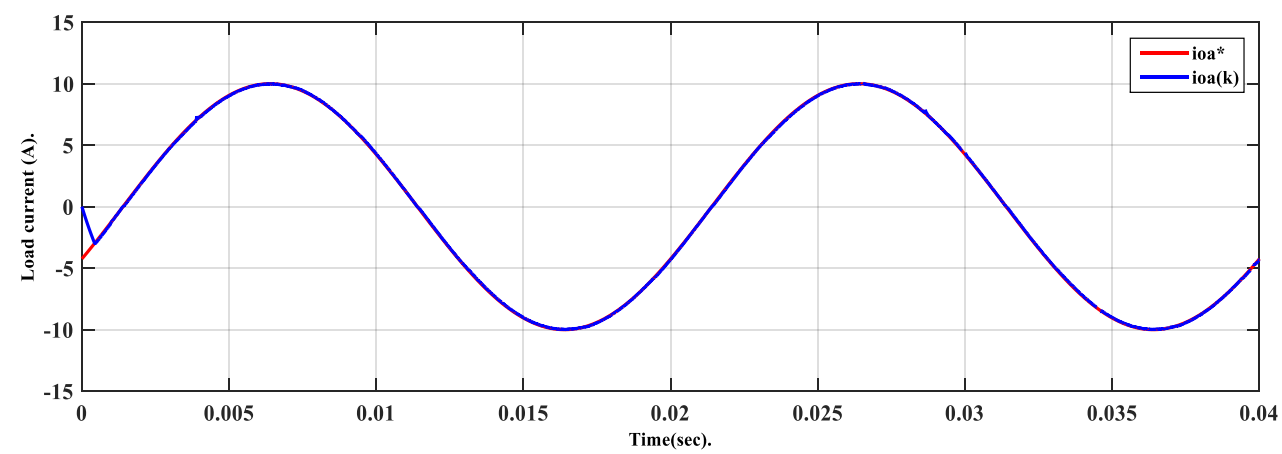

Figure 10. Ø-a current, actual (blue-line), and (red-line)

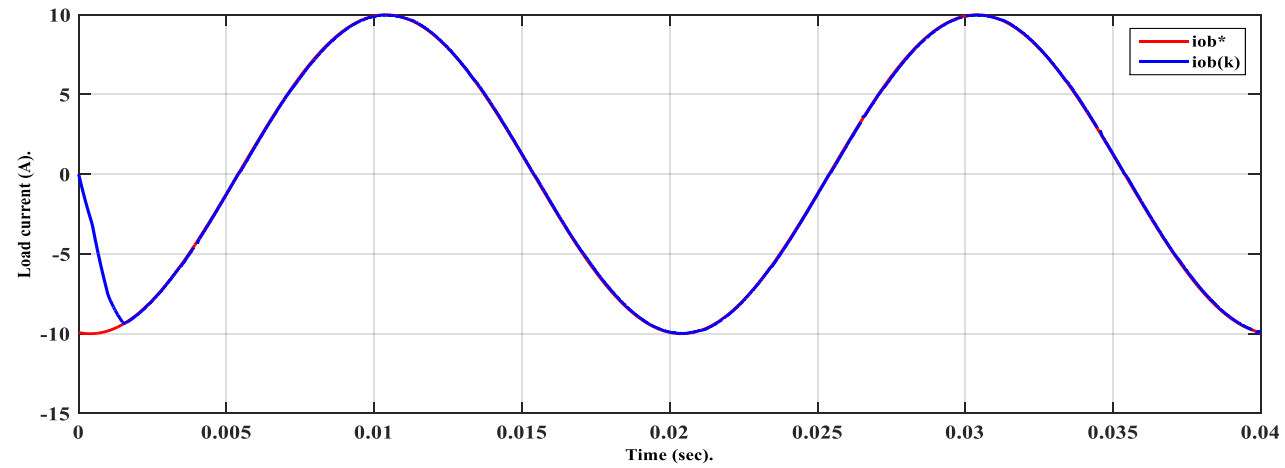

Figure 11. Ø-b current, actual (blue-line), and desired desired(red-line)

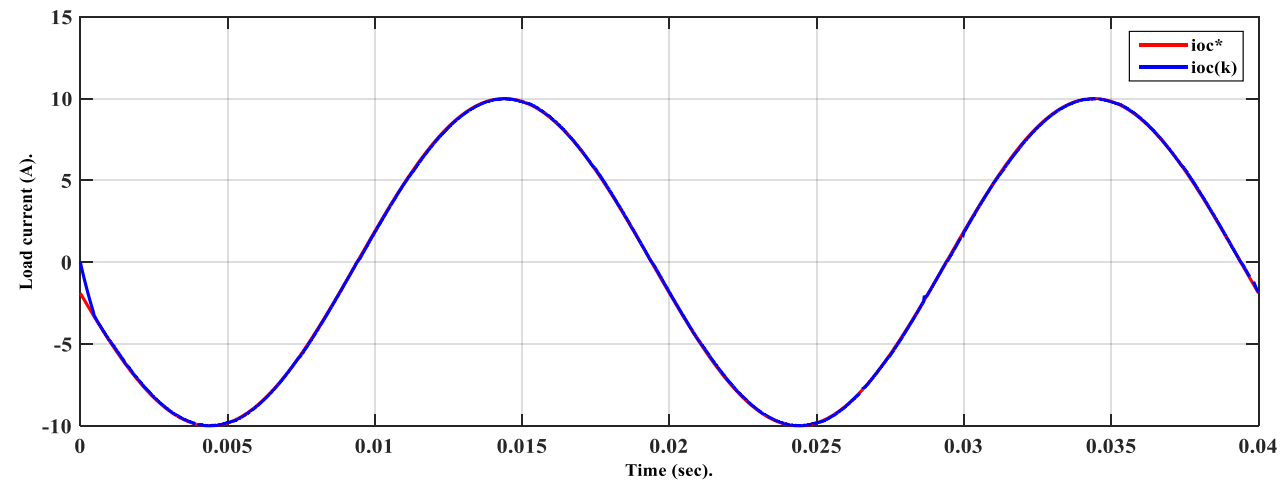

Figure $12 \emptyset$-c current, actual (blue-line), and (red-line)

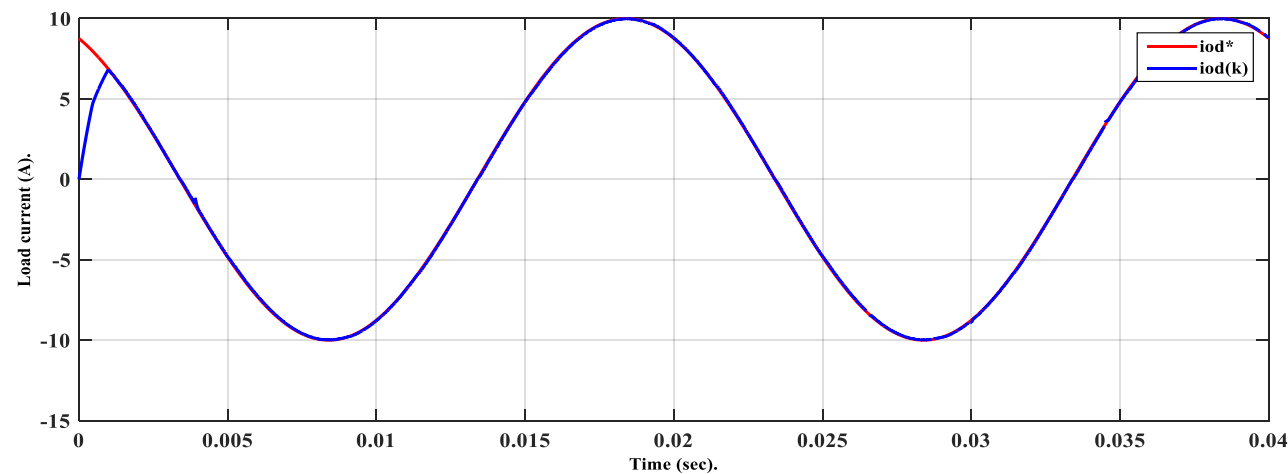

Figure13. Ø-d current, actual (blue-line), and desired desired (red-line) 


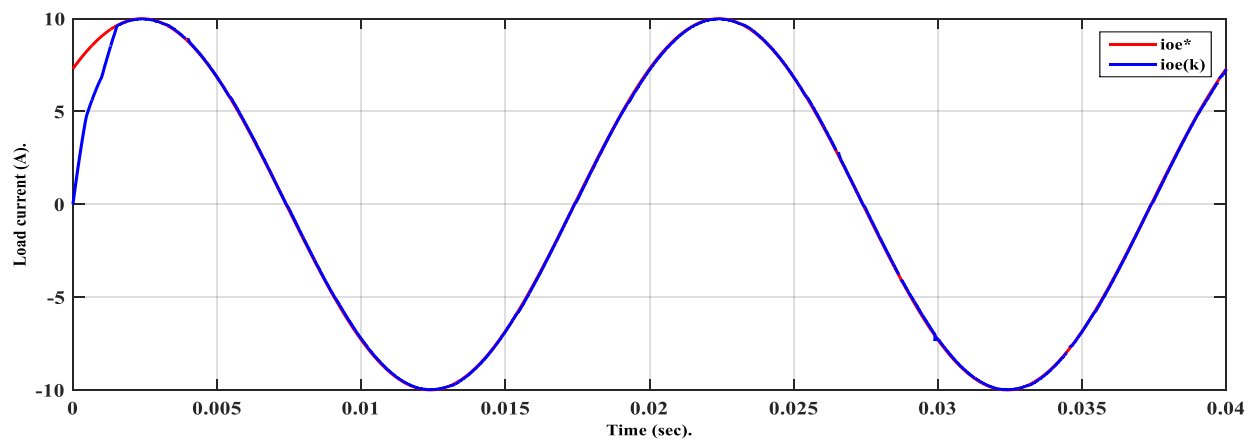

Figure 14. Ø-e current, actual (blue-line), and desired (red-line)

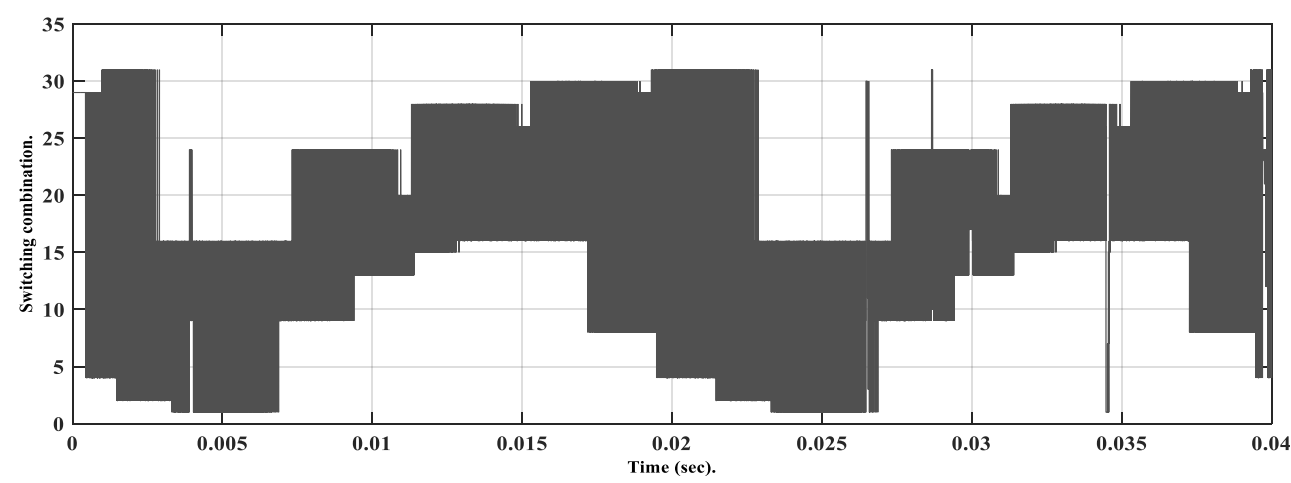

Figure 15. The chosen applied switching combination

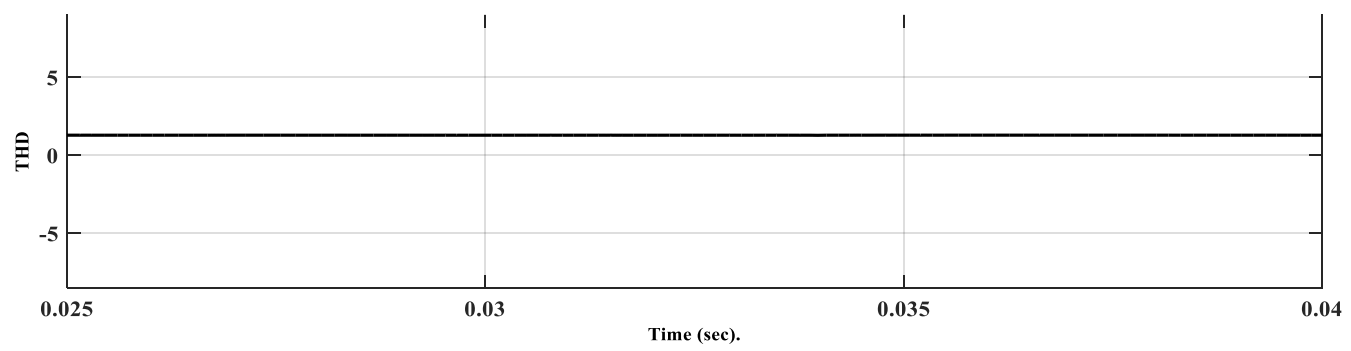

Figure 16. THD for the inverter voltage

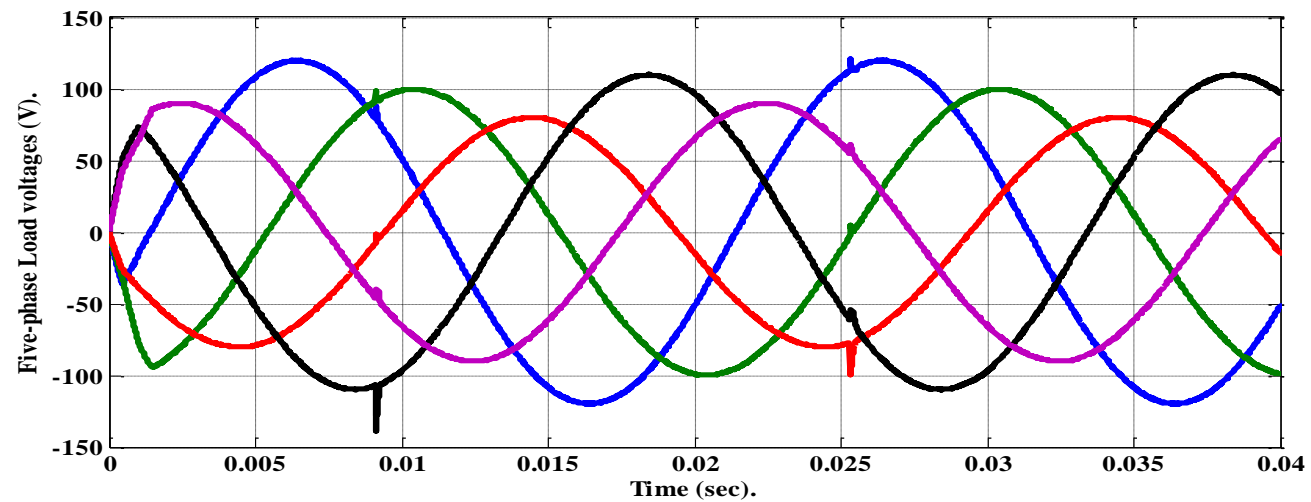

Figure 17. 5-Ø load voltages for the case of balanced desired currents with different load in each phase 


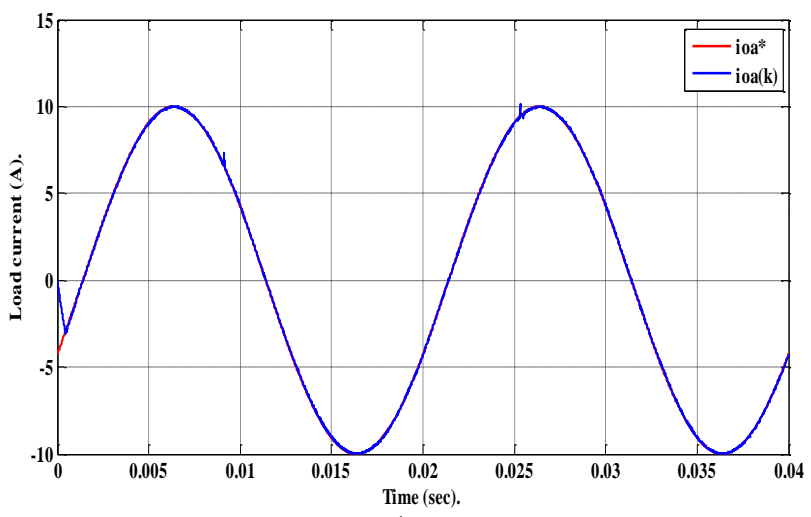

$\varnothing$-a

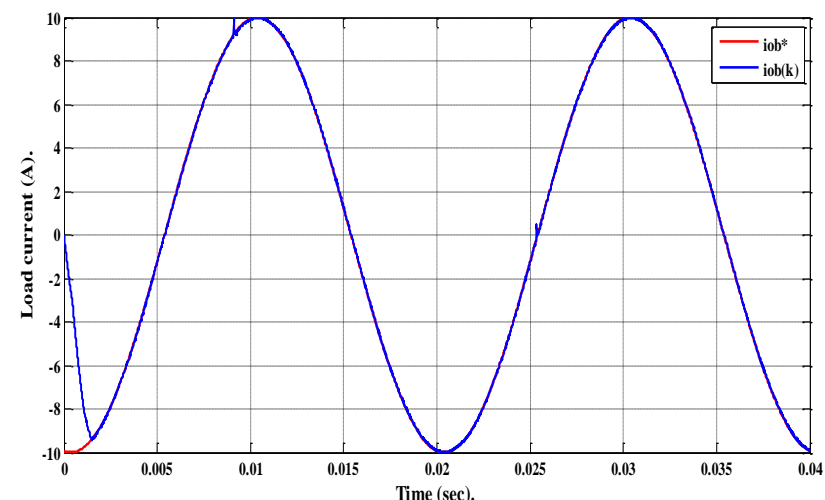

$\varnothing-b$

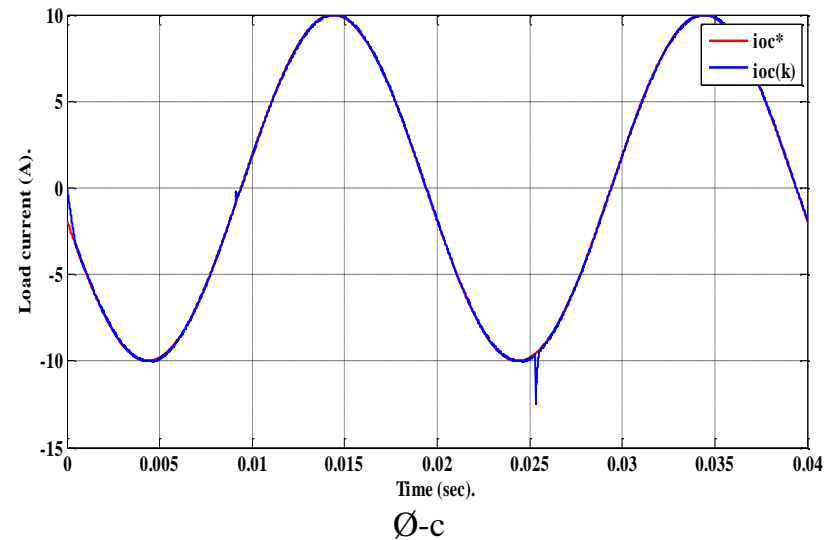

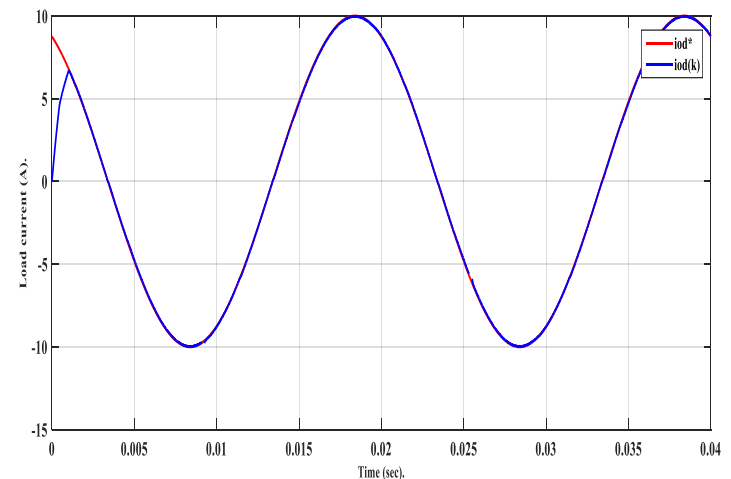

$\varnothing-d$

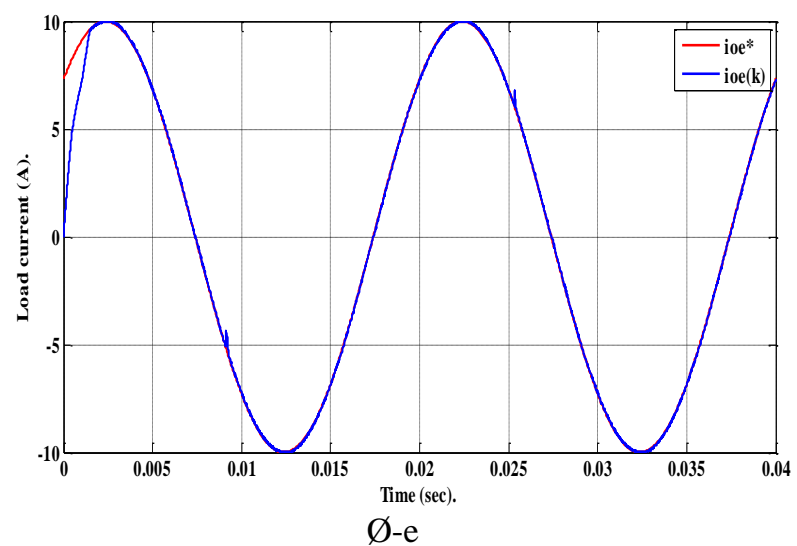

Figure 18. 5- $\varnothing$ actual load currents (blue-line) with desired currents (red-line) for the case of balanced desired currents with different load in each phase 


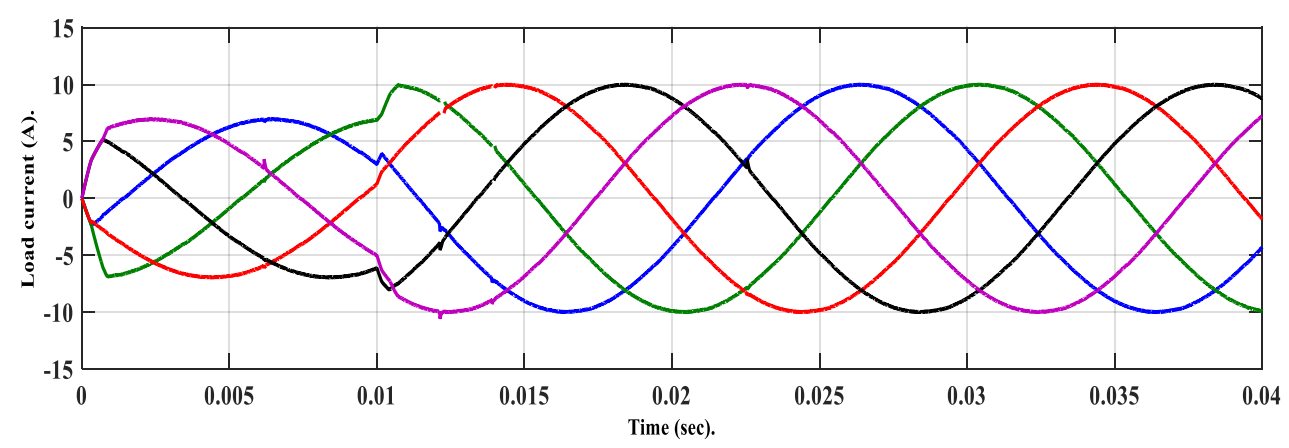

Figure 19. 5- $\varnothing$ actual load currents when a step change in the desired currents

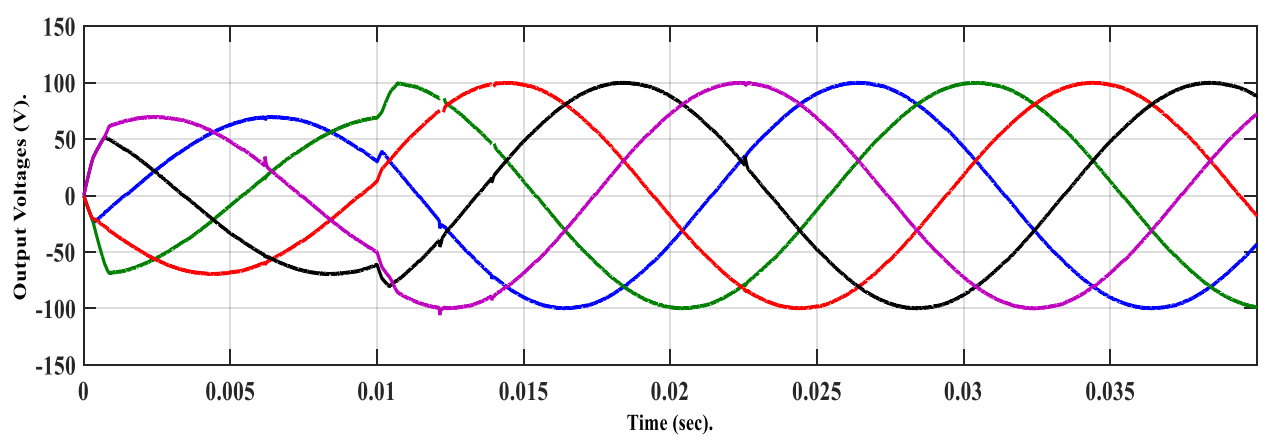

Figure 20. 5- $\varnothing$ voltages when a step change in the desired currents

\section{CONCLUSION}

The paper presents a mathematical analysis for the 5- $\varnothing$ (DC voltage input inverter), a Matlab/Simulink FCS-MPC model is built to control the 5- $\varnothing$ currents. The analysis considers a cost function optimization, adding new two constraints 1- maximum allowable output current, and 2- minimum current error constraints is presented. The proposed algorithm chooses one from the finite $(25=32)$ switching combinations produced by the 5- $\varnothing$ inverter switches, in each period $(K+1)$ the load current is predicted. This value results by matching the desired and the real current values at period $(K)$, based on that the algorithm could choose the proper switching combination that yields least cost-function error value, and then stratify this chosen combination to the DC voltage input inverter. The obtained analysis results avow the genuineness of that technique. Additionally, the application of this technique and the new control path, affirms the superiority than traditional methods in the literature. Moreover, the new constraints provide a good THD since it discards any unwanted deflections. Various examples are used to confirm the adequacy, and sufficiency of the proposed technique, for instance: Not equal desired current values while each phase contain the same load, and Sudden change in the desired values. The results demonstrated that the 5- $\varnothing$ actual currents pursue and nearly coordinate the desired values

\section{ACKNOWLEDGEMENTS}

The author would like to show appreciation to Mustansiriah University for assisting this research.

\section{REFERENCES}

[1] Prasad Rao, K. P., Krishna Veni, B., Ravithej, D.," Five-Leg Inverter For Five-Phase Supply," International Journal of Engineering Trends and Technology-Volume3Issue2- 2012.

[2] De Silva, P. S. N., J. E. Fletcher, and B. W. Williams. "Development of space vector modulation strategies for five phase voltage source inverters." IEE Conference Publication. Vol. 2. London; Institution of Electrical Engineers; 1999, 2004.

[3] Yasir M.Y. Ameen, Bashar A. Fadheel, Ali J. Mahdi, "Third harmonic injection PWM technique for maximizing DC-BUS utilization of Five-Phase VSIs," Indonesian Journal of Electrical Engineering and Computer Science, Vol. 17, No. 3, March 2020, pp. 1607 1617. 
[4] Gao, Liliang, and John E. Fletcher. "A space vector switching strategy for three-level five-phase inverter drives." IEEE Transactions on Industrial Electronics 57.7 (2010): 2332-2343.

[5] Lim, Chee Shen, et al. "FCS-MPC-based current control of a five-phase induction motor and its comparison with PIPWM control," IEEE Transactions on Industrial Electronics 61.1 (2014): 149-163.

[6] Vargas, Rodríguez, Ammann, and Wheeler, "Predictive Current Control of an Induction Machine Fed by a Matrix Converter with Reactive Power Control," IEEE Transactions on Industrial Electronics, vol. 55, no. 12, Dec. 2008.

[7] H. Abu-Rub, J. Guziñski, Z. Krzeminski, and H. A. Toliyat, "Predictive current control of voltage-source inverters," IEEE Trans. Ind. Electron, vol. 51, no. 3, pp. 585-593, Jun. 2004.

[8] R. Kennel and A. Linder, "Predictive control of inverter supplied electrical drives," in Proc. Conf. Rec. IEEE PESC Annu. Meeting, Galway, Ireland, Jun. 2000, pp. 761-766.

[9] H.-T. Moon, H.-S. Kim, and M.-J. Youn, "A discrete-time predictive current control for PMSM," IEEE Trans. Power Electron., vol. 18, no. 1, pp. 464-472, Jan. 2003.

[10] P. Wipasuramonton, Z. Q. Zhu, and D. Howe, "Predictive current control with current-error correction for PM brushless AC drives," IEEE Trans.Ind. Appl., vol. 42, no. 4, pp. 1071-1079, Jul./Aug. 2006.

[11] P. Mattavelli, G. Spiazzi, and P. Tenti, "Predictive digital control of power factor preregulators with input voltage estimation using disturbance observers," IEEE Trans. Power Electron., vol. 20, no. 1, pp. 140-147, Jan. 2005.

[12] Metri, J.I.; Vahedi, H.; Kanaan, H.Y.; Al-Haddad, K., "Real-Time Implementation of Model-Predictive Control on Seven-Level Packed U-Cell Inverter," IEEE Trans. Ind. Electron. 2016, 63, 4180-4186.

[13] Rajapakse, G.; Jayasinghe, S.; Fleming, A.; Negnevitsky, M., "A Model Predictive Control-Based Power Converter System for OscillatingWater ColumnWave Energy Converters," Energies 2017, 10, 1631.

[14] Kouro, S.; Perez, M.A.; Rodriguez, J.; Llor, A.M., "Model Predictive Control: MPC's Role in the Evolution ofPower Electronics," IEEE Ind. Electron. Mag. 2015, 9, 8-21.

[15] Bayhan, S.; Trabelsi, M.; Abu-Rub, H.; Malinowski, M., "Finite-Control-Set Model-Predictive Control for a QuasiZ-Source Four-Leg Inverter Under Unbalanced Load Condition," IEEE Trans. Ind. Electron. 2017, 64, 2560-2569.

[16] A. Abbaszadeh, D. A. Khaburi, H. Mahmoudi, and J. Rodríguez, "Simplified model predictive control with variable weighting factor for current ripple reduction," IET Power Electronics, vol. 10, no. 10, pp. 1165-1174, 2017.

[17] L. Guo, X. Zhang, S. Yang, Z. Xie, L. Wang, and R. Cao, "Simplified model predictive direct torque control method without weighting factors for permanent magnet synchronous generator-based wind power system," IET Electric Power Applications, vol. 11, no. 5, pp. 793-804, 2017.

[18] Siami, Mohsen, et al. "A Computationally Efficient Lookup Table Based FCS-MPC for PMSM Drives Fed by Matrix Converters," IEEE Transactions on Industrial Electronics.pp.1-1, (2017).

[19] J. Rodriguez, and P. Cortes, "Predictive Control of Power Converters And Electrical Drives", a John Wiley \& Sons, Ltd. Publication, first edition, 2012, ISBN 978-1-119-96398-1.

[20] M. Reyasudin Basir Khan, Jagadeesh Pasupuleti , Jabbar Al-Fattah, Mehrdad Tahmasebi "Energy management system for PV-Battery microgrid based on model predictive control," Indonesian Journal of Electrical Engineering and Computer Science, Vol. 15, No. 1, July 2019, pp. 20 25.

[21] J. Rodríguez, J. Pontt, C. Silva, P. Correa, P. Lezana, P. Cortés, and U. Ammann, "Predictive Current Control of a Voltage Source Inverter," IEEE Trans. on Industrial Electronics, vol. 54, no.1, Feb. 2007.

[22] P Chenchu Saibabu, Hitesh Sai, Saksham Yadav, C. R Srinivasan," Synthesis of model predictive controller for an identified model of MIMO process," Indonesian Journal of Electrical Engineering and Computer Science, Vol. 17, No. 2, February 2020, pp. 941 949.

[23] T. Geyer, "Low Complexity Model Predictive Control in Power Electronics and Power Systems", PhD. Thesis, Swiss Federal Institute of Technology, 2005.

[24] S. Kouro, P. Cortés, R. Vargas, U. Ammann, and J. Rodríguez, "Model Predictive Control-A Simple and Powerful Method to Control Power Converters," IEEE Trans. on Industrial Electronics, vol. 56, no. 6, Jun. 2009.

[25] Omar, Riyadh G., and Rabee'H. Thejel. "Finite Control Set Model Predictive Current Control FCS-MPC Based on Cost Function Optimization, with Current Limit Constraints for Four-Leg VSI." Iraqi Journal for Electrical \& Electronic Engineering, Vol.12.No.1 (2016). 